\title{
Matthias Corvinus - tradierte und vergessene Züge eines legendären Herrschers der Ungarn
}

\author{
TIBORC FAZEKAS (Hamburg)
}

\section{Zur Komplexität des Phänomens}

König Matthias, der in der ungarischen Geschichtsschreibung als Matthias I. oder als Matthias Corvinus bekannt ist, stellt eine der bedeutendsten Gestalten in der Geschichte des selbständigen Ungarischen Königreichs dar. Sowohl seine Person (1443-1490) als auch seine 32 Jahre währende Herrschaft (1458-1490) setzten einerseits die vor ihm für das Land über vier Jahrhunderte lang entstandenen typischen Formen der königlichen Machtausübung fort, sie enthalten allerdings auch andere Merkmale, die deutlich von den Vorgängern abweichen und nicht in die gewöhnliche Tradition der Überlieferung über Herrscher passen. Matthias ist in seiner Komplexität eine einmalige Erscheinung in der Geschichte Ungarns, aber auch seine Reflexion in der Überlieferung ist in ihrem Reichtum an Facetten einmalig (Abb. 1, S. 399). Nahezu natürlich wird jeder ,große“ König traditionell mit dem Attribut des Einmaligen oder des "Großen" bezeichnet. Matthias hat in der ungarischen Geschichtsschreibung den Beinamen „Groß“ nicht bekommen, aber er war ein großer König und eine großartige Persönlichkeit, und die Mischung aus diesen beiden Komponenten hat im Laufe der Jahrhunderte ein vielseitiges, buntes, mit festen Eigenschaften ausgestattetes und doch teilweise widersprüchliches Bild über ihn entstehen lassen. Die einschlägige Literatur ist geradezu erdrückend, denn Hunderte von Büchern haben sich mit Matthias befasst, eine Hilfe und gleichzeitig ein Hindernis für alle, die ein objektiveres Bild dieses Königs zeichnen wollen. Mit seiner Herkunft und mit der Person von König Matthias hängt wohl jene auffällige Besonderheit zusammen, dass auch in der Tradition der verschiedenen mitteleuropäischen Völker die Spuren von König Matthias überall zu finden sind. Diese, in den Folkloretexten auftauchende und mit positiven Eigenschaften ausgestattete Person heißt bei den Ungarn „Mátyás király“, bei den Rumänen „Matei Corvin“, im Slowakischen nennt man ihn „Matej Korvín“, im Böhmischen taucht er als „Matyáš“, im Kroatischen als „Matija Korvin“, im Slowenischen als „Kralj Matjaž“ auf. Insbesondere in den südslawischen Sprachen sind recht viele epische Texte über ihn als folkloristischen Helden des Kampfes gegen die Osmanen erhalten. Trotz der durch diese Tatsachen gegebenen Vergleichsmöglichkeiten beschränken sich meine fol- 
genden Ausführungen allein auf die in Ungarn und auf die im Ungarischen nachweisbaren Formen und Elemente einer gemeinsamen Erinnerung.

\section{Ein Versuch zur „objektiven“ Darstellung von König Matthias}

Die Bedeutung Matthias' für die Nachwelt bzw. die erhaltenen und die verdrängten Komponenten seiner Figur können etwas verständlicher werden, wenn wir erst versuchen, seine Herrschaft kurz und objektiv zu schildern. Dabei müssen allgemeine und persönliche Elemente gleichermaßen berücksichtigt werden.

Eine entscheidende Rolle im Leben und Herrschaft von Matthias haben die Spannungen um das Erbe des Throns des ungarischen Königreichs gespielt. Die eigene Dynastie, die Árpáden, sind 1301 ausgestorben, im 14. Jahrhundert hat das ungarische Königreich mit zwei herausragenden Herrschern aus der Anjou-Dynastie sogar eine neue Blüte erlebt. Doch auch dieses Geschlecht hat nach 1380 keinen männlichen Erben mehr für den ungarischen Thron gehabt. In der Zwischenzeit und immer, wenn der Anspruch einer Dynastie erloschen war, meldeten sich andere Herrscherhäuser mit ihrem Thronanspruch an. 1387 stieg Sigismund von Luxemburg auf den ungarischen Thron, der bis zu seinem Tod (1437) den Titel des ungarischen Königs behielt, obwohl er in den letzten vier Jahren seines Lebens auch Kaiser des Deutschen Reiches gewesen ist. Auf jedem Fall traten nach dem Tode Sigismunds mehrere benachbarte Herrscherdynastien (Habsburger, Jagiellonen, Georg Poděbrad) mit direktem Anspruch auf den Thron hervor. Der Konflikt zwischen Matthias und Friedrich III. und somit mit der Habsburg-Dynastie hat in Bezug auf seine Person sogar zu einem nachhaltigen Dissens zwischen der deutschen und der ungarischen Geschichtsschreibung geführt, die die Aktionen des ungarischen Königs traditionell nahezu diametral anders bewerten. Matthias' Wahl zum ungarischen König war auf jeden Fall ein außenpolitisch riskanter Schritt. Er hat zwar seine Verteidigungskämpfe erfolgreich ausgefochten, aber nicht mit dem Krieg aufgehört, denn bis zu seinem Lebensende führte er militärisch zwar erfolgreiche, aber nicht genügend ertragreiche und vor allem nicht lange haltbare Eroberungen (Mähren, Schlesien, Lausitz, Tschechien, Kärnten, Steiermark, die Einnahme Wiens) durch. Es mag sein, dass hinter diesen Aktivitäten auch die aus der Geschichte des eigenen Vaters entstandene Erkenntnis gewirkt hat, dass Ungarn alleine, aber auch mit der gelegentlichen und sehr unberechenbaren Hilfe der „christlichen Welt“ (vor allem der Päpste) nicht mehr im Stande war, die osmanischen Angriffe abzuwehren. Ohne einen für die Türken schwer erreichbaren und industriell wesentlich weiter entwickelten Bestandteil seines Herrschaftsgebiets (wie z.B. Schlesien) konnte der ungarische König seine Positionen dem Sultan gegenüber nicht lange halten.

Das zweite Problem in der Außenpolitik bedeutete nämlich die zunehmende Gefahr seitens des Osmanischen Reiches. Die sich seit mehreren Jahr- 
zehnten regelmäßig wiederholenden Angriffe der Türken, die abnehmende Bereitschaft und militärische Fähigkeit Ungarns, eine „Vorverteidigung“ (also einen Kampf außerhalb der eigenen Landesgrenzen) zu praktizieren, die grundlegend veränderte und unberechenbar gewordene, miteinander gerade in Bezug auf die osmanischen Angebote und Forderungen rivalisierenden Alliierten in der Moldau und auf dem Balkan untergruben die früheren, sicheren Positionen Ungarns und wurden Mitte des 15. Jahrhunderts selbst zu einer Gefährdung für das Land.

Entsprechend den Gesetzen des feudalistischen Systems herrschten im späten Mittelalter auch in Ungarn immer wieder fast anarchische Verhältnisse durch die Macht der Oligarchien. Die Annahme, der minderjährig zum König gewählte Matthias lasse sich von den Verwandten und älteren Würdenträgern des Staates leicht instrumentalisieren, wurde sehr bald durch Enttäuschung, später sogar durch Widerstand abgelöst. Der König trat für ein stark zentralisiertes Herrschaftssystem ein, denn den drohenden Gefahren von außen hätte man nur mit einem wirtschaftlich, organisatorisch und militärisch starken Land begegnen können. Paradoxerweise haben diese Notwendigkeiten für das auBenpolitische Überleben gleichzeitig den innenpolitischen Widerstand genährt. Wenn man die Komplexität der zu bewältigenden Aufgaben des ungarischen Königs zu dieser Zeit betrachtet, wird klar, dass es fast gleichgültig war, was für eine konkrete Aktion Matthias gerade durchzufuihren gedachte, es gab immer Kreise und Kräfte um ihn herum, die eher etwas anderes von ihm verlangten. Somit hatte der Herrscher immer wieder auch mit einer inneren Opposition zu kämpfen, was seine Positionen schwächte oder zumindest instabil machte. Matthias ist fast seine ganze Herrschaftszeit lang mit der ihn umgebenden (und ursprünglich seine Wahl zum König vorbereitenden und durchsetzenden) höchsten adeligen Schicht des Landes in Konflikt gestanden, die höchsten Würdenträger des Staates wurden immer häufiger von neueren, aus dem mittleren Adel stammenden Personen abgelöst.

Die dritte Ehe von König Matthias im Jahre 1476 mit Beatrix, der Tochter des neapolitanischen Königs Ferdinand I., sollte vor allem einen Nachfolger mit Rang und dynastischer Zugehörigkeit sichern. Diese Hoffnung ist zwar nicht erfüllt worden, aber mit dem Hof der Königin kam ein außergewöhnlich starker kultureller Einfluss aus Italien nach Ungarn. Der Humanismus zeigte in mehrfacher Hinsicht in Ungarn zum ersten Mal seine Wirkung außerhalb Italiens, der Hof des ungarischen Königs wurde in dieser Zeit ein wahres Zentrum dieser geistigen Strömung. In den letzten anderthalb Jahrzehnten seines Lebens entwickelte sich Matthias zu einem wahren Renaissance-Herrscher, was ihm einerseits einen beispiellosen internationalen Ruhm einbrachte, andererseits stärkten die damit verbundenen finanziellen Ausgaben und die Begünstigung der aus Italien gekommenen „Fremden“, sowie die daraus entstandenen negativen Folgen für die Verteidigungsbereitschaft des Landes den inneren Widerstand. Sein verzweifelter Plan, die Krone an seinen außerehelichen Sohn ,Johannes Corvinus" vererben zu lassen, scheiterte an dem inneren und damit eng 
verbundenen äußeren Widerstand, sein Königreich zerbrach wenige Monate nach seinem Tod.

Auch die persönlichen Elemente der Figur von Matthias sind sehr komplex und widersprüchlich. Der in Klausenburg geborene und Wien begrabene Matthias ist als zweiter Sohn des als Gouverneur Ungarns und nach der Befreiung von Nándorfehérvár (Belgrad) 1452 als „Türkenbezwinger“ bekannten János Hunyadi und seiner Frau, Erzsébet Szilágyi, zur Welt gekommen (Abb. 2, S. 399). Der Vater von Matthias, János Hunyadi, wurde im Krönungsjahr (1387) von König Sigismund (1368-1437, ab 1433 dt. Kaiser) geboren, und seine Laufbahn ist sehr eng mit der Herrschaftszeit dieses Königs verbunden. Beide Söhne von János Hunyadi hatten eine hervorragende Ausbildung genossen und besaßen alle Perspektiven, die dem Nachkommen eines mächtigen Kriegsherrn, einem der reichsten Adeligen und dem politischen Führer eines Landes (zwar ohne Königstitel) in Aussicht gestellt werden konnten. László, der ältere Sohn, wurde in den Machtkämpfen hingerichtet, Matthias, der jüngere Sohn, wurde als „Geisel“ in Wien und in Prag gefangen gehalten. Er musste zu seinen avisierten Möglichkeiten einen schweren gefahren- und lehrreichen Weg gehen.

Obwohl beide Elternteile zu den mächtigsten Familien des ungarischen Königreichs gehören, ist Matthias kein Mitglied einer Dynastie, und als „homo novus" wurde er deshalb von den europäischen Herrscherfamilien entsprechend herablassend behandelt, ein Umstand, der wiederum die Persönlichkeit des ehrgeizigen Matthias nachhaltig mitgeprägt hat. Er ist als „vom Volk (d.h. von einer Liga aus dem Kreis der Adeligen) gewählter König" der erste in der Geschichte Ungarns. Auch diese Umstände könnten bei seinem oft erwähnten Ehrgeiz eine Rolle gespielt haben. Denn Vorstellungen, Pläne hat Matthias reichlich gehabt, den Willen zu ihrer Durchführung ebenso, und er war auch nicht zimperlich, wenn er dabei Widerstand brechen musste. Trotzdem galt er eher als vergebender und nicht als rachsüchtiger oder brutaler Gegner in seiner Zeit. Er war ein wirklich typischer absoluter Herrscher, der allerdings ,aus dem Volke emporgestiegen“" (also kein Angehöriger einer Dynastie) war, der in seinem Land diese absolute Macht geschickt, gerecht und auch mit Kultur verbunden hat ausüben können. Seine eigentlichen, die Zukunft seines Landes sichernden Aufgaben wären allerdings nur in Eintracht mit dem internationalen Umfeld lösbar gewesen, und hier haben die Bemühungen von König Matthias für Ungarn nur vorübergehende, nicht lange haltbare Ergebnisse erbracht. Seine Größe ist auch nach dem Maßstab eines Historikers unumstritten:

Matthias Hunyadi dürfte nach Stefan, dem Heiligen, und Ludwig, dem Großen, der bedeutendste König Ungarns gewesen sein. Durch seine kontinuierlich verfolgten Reformmaßnahmen hat er in seinem von Breslau über Brünn, Wien und Ofen bis nach Ragusa und weit in den Balkan hineinreichenden Länderkonglomerat lange nachwirkende Neuerungen auf politischem, gesellschaftlichem, wirtschaftlichem und rechtlichem Gebiet eingeleitet. Ihm ist darüber hinaus zugute zu halten, der Mit-Initiator eines geistig-kulturellen Umbruchs im östlichen Mittel- 
europa gewesen zu sein, der dem Humanismus und der Renaissance den Weg bereitete. Seine Verdienste als Freund der Wissenschaften, Universitätsgründer, Bauherr, Kunstsammler und Büchernarr, der mit den führenden Geistern seiner Zeit das persönliche Gespräch pflegte oder in lebhaftem Briefwechsel stand, sind ebenso hoch zu bewerten wie seine Leistungen als Politiker und Militär. ${ }^{1}$

Der Sturz Ungarns in die Teilung und die osmanische Besetzung des Landes fast vierzig Jahre nach dem Tod von Matthias hat rückblickend seine Zeit verständlicherweise immer als Idealzustand erscheinen lassen.

\section{Die Strukturen der Erinnerung}

König Matthias hat unter den mittelalterlichen Herrschern Ungarns ein beispielloses „Nachleben“ in der Erinnerung der Menschen bis in unsere Tage hin behalten. Diese Erinnerung an den König stützt sich allerdings nicht auf von der Kirche kanonisierte Legenden und andere religiöse Formen, sondern ist von stark säkularem Charakter. Er wird in dieser Tradition nicht als Abgott, Heiliger, als ein Wunder unter Menschen, sondern eben als ein vernünftiger, meist die Gerechtigkeit durchsetzender Herr geschildert, der auffällig viel Gemeinsames mit denen hat, die nicht als „Herren“ zur Welt gekommen sind.

Ein Unbekannter hat ein Lied Zum Gedenken an den Tod des Königs Matthias 1490 verfasst. Bereits in diesem, nach dem Vorbild von Klageliedern gefassten Text finden wir einige auf seine Person zugeschnittene Komponenten und Motive seines späteren Andenkens wieder:

...Ungarns heller Stern, der warst du,

Schutzschild auch dem Feind zu wehren,

Warst Beschützer aller Armen,

Halfst dem Land zu Macht und Ehren.

Flößtest Mut ein den Verzagten,

Warst die Zierde der Magyaren,

Unerbittlich gegen Polen,

Schütztest Ungarn vor Gefahren.

Standest stets in hohem Ansehn

Unter Königen hienieden,

Zuflucht, die du warst dem Volke,

Ruhe nun in Gottes Frieden! ${ }^{2}$

Ich werde mich im Weiteren mit den Besonderheiten der Überlieferung der Figur von König Matthias in der ungarischen Tradition in sechs typischen, unterschiedlichen und doch miteinander eng verknüpften Kontextzusammenhängen befassen, selbstverständlich ohne Anspruch auf Vollständigkeit. Ein

1 Hoensch 1998, S. 268-69.

2 Klaniczay 1978, S. 75. 
Narrativ in Bezug auf König Matthias als Beispiel, Rat gebende Quelle, historische Figur oder Symbol der individuellen und nationalen Tugenden, findet auch in unseren Tagen hauptsächlich in den folgenden Bereichen statt:

- Am ältesten und an Literatur am umfangreichsten ist die wissenschaftliche, historische und geschichtswissenschaftliche Aufarbeitung von König Matthias, an der sich alle Teildisziplinen (Heraldik, Militärforschung, Diplomatik etc.) beteiligen

- Eine Überlieferung des Herrschers in den kulturhistorischen Wissenschaftsbereichen (Humanismus- und Renaissanceforschung, Kirchengeschichte, Bibliothekswissenschaft, etc.) ist ebenso umfangreich und gleichzeitig sehr vielschichtig

- Nahezu seit dem Thronantritt von Matthias und teilweise parallel zu den anderen Formen ist auch eine vielschichtige, international weit geflochtene literarische Tradition um seine Person entstanden

- Eine volkstümliche epische Tradition ist eine eigene, breite und sehr bunte Sammlung von „nicht-kanonisierten“ Texten, auch außerhalb Ungarns weit verbreitet

- Die Darstellungen des Königs in den bildenden Künsten und in der Allgemeinbildung (Schulbücher) sind teilweise moderne Erscheinungen, ihre Vorstellungen prägen aber die Erinnerung an den König immer deutlicher

- Auch die Elemente einer - immer anders gewichteten - politischen Tradition sind im Zusammenhang mit Matthias erkennbar.

\section{Das Bild König Matthias' in der Geschichtsschreibung}

Bereits die Zeitgenossen von Matthias (Freunde und Feinde gleichermaßen!) haben über ihn umfangreiche Informationen im In- und Ausland verbreitet, wodurch die „Zutaten“ zur Entstehung eines für die Zukunft geschaffenen Herrscherbildes erstellt wurden. Diese Quellentexte besitzen neben dem historischen zumeist gleich auch einen literarischen Wert und liefern somit gleichzeitig Vorlagen für die hier als ein weiterer Aspekt zu behandelnde literarische Tradition. Die Chroniken von Antonio Bonfini (1434-1503) ${ }^{3}$, Petrus Ransanus (1428-1492) , János Thúróczy (um 1435 bis um 1488 - (Abb. 3, S. 400)) ${ }^{5}$, Gáspár Heltai (1510-1574) ${ }^{6}$, die in Italien geschriebene Arbeit von Marzio Galeotto (1427?-1497?) über die Sprüche und Taten des Königs ${ }^{7}$ etc. haben eine bis dahin nie gesehene etwa zeitgenössisch entstandene Informationsmenge über einen ungarischen Herrscher für die damalige Welt geliefert. Wie sehr

3 Bonfini 1936-1941.

4 Ransanus 1977.

5 Thuróczy 1473. Diese „....galt wohl als das weitest bekannte Buch über die Geschichte Ungarns..." zitiert von Bak 1973, S. 106, Fußnote 43.

6 Heltai 1575.

7 Galeotto 1485. 
allerdings die Beurteilung einer so großen Persönlichkeit von aktuellen und persönlichen Umständen abhängt, zeigt ein Vergleich: der Zeitgenosse und Gast des ungarischen Königshofes, Bonfini, die umfangreichste Quelle für den Ruhm des Königs, widmet Matthias Hunderte von Seiten, während dieselbe Person etwa zweihundert Jahre später in einem Ungarn gegenüber eher ,reservierten" Bericht nur auffallig kurz dargestellt wurde:

Matthias Corvinus Vier und dreissigster König in Hungarn. Matthias Corvinus, Johannis Hunniadis Sohn /ward/ da er noch zu Prag gefangen lag/ zum Ungarischen König erwehlet/ hatte grossen Sieg wieder den Türcken/ welchen er auch zum offteren erleget hat/ starb durch einen jähen Zorn/ Anno 1490 liegt zu Stuhlweissenburg begraben. ${ }^{8}$

Die wichtigsten Elemente der so entstandenen historischen Überlieferung wirkten nachhaltig weiter, unsere heutige Vorstellung über den König basiert auf einer Mischung von faktischen und konstruierten Behauptungen der Zeitgenossen. Neben den bereits erwähnten, von der heutigen Geschichtswissenschaft anerkannten Tugenden des Königs ${ }^{9}$ leben in dieser Tradition auch andere Eigenschaften des Königs sowie Besonderheiten seiner Herrschaft weiter. So wird er dank der Umstände seiner Wahl (,,vox populi vox dei“, denn auf dem Eis der zugefrorenen Donau wurde er vom Landtag - in Abwesenheit - zum König gewählt) ein Beispiel dafür, dass nach einer langen Zeit der dynastischen Erbfolge auf dem ungarischen Thron, die „Nation“ (d.h. die Versammlung der Adeligen) als Souverän, der sich uneingeschränkt auf sein altes Recht stützt, einen würdigen, großen König aus ihren eigenen Reihen wählen kann. Die in der ungarischen Gesellschaft sehr lange, bis in das 20. Jahrhundert hinein eine entscheidende Rolle spielende adelige Schicht brauchte dringend Figuren wie Matthias, um ihre „Berufung“ zur Führung der Nation (und zur Begründung der ihr dafür zustehenden Privilegien) zu beweisen. Matthias ist deshalb in den folgenden Jahrhunderten eine Verkörperung der adeligen Tugenden geworden, seine Schilderungen betonen seine Macht als König der Ungarn (er wurde als ,maiestas Matthias hungarorum potentissime rex“ im Ransanus-Codex um 1490 bezeichnet - (Abb. 4, S. 401).

Auch die Rede seines Onkels, Mihály Szilágyi, hebt bei der erwähnten „,ungewöhnlichen“ Wahl von Matthias die Interessen und Vorstellungen der Adeligen, um ihn zu wählen, in „vier Gründen“ (nach der Beschreibung Bonfinis) hervor. Demnach soll:

a) kein Fremder zum König gewählt werden;

b) Matthias ist der Nachkomme des Türkenschlägers, János Hunyadi, ist also ein Garant für die Sicherheit des Landes;

c) mystische Vorhersagungen deuteten an, dass er ein großer König werden wird, also der Himmel unterstützt ihn auch, und

8 Happelius 1688, S. 183.

9 Siehe den Haupttext zu Anmerkung 1. 
d) er ist zwar ein Kind noch (Matthias war gerade 15 Jahre alt), aber man kann ihn so viel besser ändern, erziehen. ${ }^{10}$

Ohne Zweifel scheint die Annahme richtig zu sein, dass Matthias versucht hat, das Vorbild Kaiser Sigismunds zu befolgen, manchen Legenden nach ist er sogar ein uneheliches Kind von diesem gewesen, ${ }^{11}$ seine Laufbahn brachte ihn vom Landadel beinahe bis zum Kaisertitel des Deutschen Reichs, und gleichzeitig war er ein Ritterkönig im Sinne einer anderen Tradition, der von Ludwig dem Großen. Fast immer hat er seine Unternehmungen (Kriege, Belagerungen, Verhandlungen etc.) persönlich geleitet, dadurch ist seine Bekanntheit im Lande und auch international deutlich gestiegen.

Für die Überlebenden und für die Nachwelt verkörpert Matthias die letzte Konzentration des Königreichs Ungarn vor dem Zerfall, zahlreiche Kriege hat er geführt und eine stehende, bezahlte Armee (Schwarzes Heer) aufgestellt. Somit wurde er geeignet, die Sehnsüchte der Nation (und des nationalen Denkens) nach Freiheit und Unabhängigkeit in den darauf folgenden zerstrittenen und leidensreichen Jahrhunderten zu symbolisieren. Als Vertreter des nationalen Adels, als letzte Toposfigur für das ,,unabhängige“ Ungarn hat er in den folgenden vier Jahrhunderten, als die Ungarn für ihre Unabhängigkeit gegen Habsburg kämpfen, eine klare Vorbildrolle übernehmen können.

Matthias hat in fast allen Bereichen seiner Machtausübung schnell und entschlossen die Initiative ergriffen, er hat seine Entscheidungen zielbewusst getroffen, aber er beharrte nicht immer stur auf seinen gesetzten Zielen, er berücksichtigte immer die Veränderungen während seiner Handlungen und machte dabei häufig ungewöhnlich erscheinende Züge (Winterfeldzüge, unerwartete Rückzüge, Friedensverträge und Abkommen auf Zeit), sehr häufig gegen die Interessen seiner innenpolitischen Umgebung und oft gegen die Vorstellungen seiner benachbarten Herrscher. Gegen Ende seiner Herrschaft wurden seine Entscheidungen zunehmend von der Sorge um seine Nachfolge geprägt: ohne einen legitimen Sohn kann sein Werk zerfallen, deshalb ist bei seinen Entscheidungen in dieser Zeit etwas mehr Verkrampftheit zu spüren.

Weniger stark wurde weitertradiert, dass er gegen Ende seiner Herrschaft oft sehr eruptiv auf Ereignisse, Meinungen und Vorschläge reagiert hat, zahlreiche hochrangige Gefolgsleute seiner Herrschaftszeit haben für diese zunehmende „Wandelbarkeit“ der königlichen Gunst mit ihrem Amt bezahlen müssen. Dass seine wichtigste Stütze in staatlichen Angelegenheiten, der amtierende Primas von Ungarn und Erzbischof von Esztergom, János Beckensloer (Johannes VIII. Alemannus) $1476 \mathrm{zu}$ dem außenpolitisch problematischsten Konkurrenten von Matthias, dem deutschen Kaiser Friedrich III., flüchtete, hat das Verhältnis des Herrschers zu seinen unmittelbaren Untertanen nachhaltig negativ beeinflusst. Diese Angelegenheit war allerdings politisch und wirt-

10 Dümmerth 1985, S. 133.

11 Kardos 1983, S. 65. 
schaftlich ein gleichermaßen schwerer Rückschlag für ihn, denn der Primas war

...unter dem Vorwand, eine Wallfahrt nach Aachen zu unternehmen, mitsamt seinem Privatvermögen und dem Graner Domschatz, dessen Wert auf 300.000 Gulden veranschlagt wurde... zu Kaiser Friedrich III. nach Wien geflüchtet (...). ${ }^{12}$

Dieser Vorfall zeigt auch, dass Matthias, dem Gewicht der Angelegenheit entsprechend mit besonders hartnäckiger Ausdauer den Verrat seines unmittelbaren Vertrauten hat verfolgen können. Es ist nicht auszuschließen, dass die harten Feldzüge gegen österreichische Territorien und die Eroberung Wiener Neustadts und später Wiens (nach 1487 - mit Versetzung des Regierungssitzes nach Wien - (Abb. 5, S. 402) mit der anschließenden Verlegung des königlichen Hofes dorthin psychologisch mit diesem Konflikt eng zusammenhängen, denn:

...für Matthias bedeutete der offene Übertritt eines seiner bewährten Ratgeber und Geheimnisträger in das Lager seines unversöhnlichen kaiserlichen Gegners einen ungeheuerlichen Prestigeverlust und außerordentlichen Affront, welche er nicht stillschweigend hinnehmen konnte. Beckensloer, der den Titel des Erzbischofs von Gran nicht ablegte, wurde zu einem der einflussreichsten Berater und bedeutenden Geldgeber des Kaisers, der ihn zum Koadjutor und Administrator des 1469 gegründeten kleinen Bistums Wien und zum Kanzler der Universität ernannte; bei seinem Tod 1489 als Erzbischof von Salzburg war der von Matthias immer wieder von neuem geschürte Konflikt noch nicht beigelegt. ${ }^{13}$

Mit dem offenbaren Ehrgeiz, aber auch mit der fehlenden dynastischen Herkunft hängt die Anhängung eines auf römische Vorfahren zurückgeführten Beinamens von Matthias (Corvinus) in der Geschichtsschreibung zusammen. Im Ausland haben über ihn zusätzlich sein prunkvoller Hof, seine Gefolge, seine Freunde und Feinde ein buntes, mit vielen Klischees der Renaissance ausgestattetes Bild hinterlassen. Die Humanisten, die in aufgesucht haben, sind weitergereist, sie haben Matthias gewidmete Arbeiten publiziert, der enge Briefkontakt zwischen den Gelehrten sowie seine diplomatischen Aktivitäten haben ihn kontinentweit bekannt gemacht. Die ersten Biographen des Hofes von Buda lieferten reichlich Material für andere Geschichtsschreiber und Gelehrte, die erhaltenen diesbezüglichen Dokumente der „zweiten Welle“ seiner Würdigungen spiegeln von Italien bis England einen starken, gebildeten und das Vorbild eines Königs verkörpernden Herrschers wieder. Als Beispiel dazu kann die englische Übersetzung der Opera horarum subcivivarum von Philip

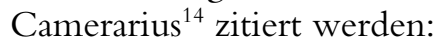

This king was well learned, exceeding studious, loved good letters and Sciences with an ardent affection, and to the professors thereof hee gave great gifts: yea, and

12 Hoensch 1998, S. 147.

13 Ebd., S. 148.

14 Camerarius 1621. 
he caused search to be made in all places for the Bookes of the Ancients, and commanded to buy them, without sparing for costs, to erect a stately Librarie, which afterwards was wasted and spoiled by the Turkes. Among other things he was not ignorant, that the truth and free libertie of speech had but small accesse into the houses of kings and princes and therefore... hee would... when he was ahunting ride away from his traine, and goe to some paisants house, or to some village, where he would passé the night in questioning (by way of familiar talke) with the poore and sillie people, of the king and what was thought of and said of him, and of its government... ${ }^{15}$

Die spätere romantische Geschichtsschreibung im 19. Jahrhundert und die Herausbildung einer standeszentrischen ,adeligen“ historischen Tradition haben mit Hilfe der allgemeinen Bildung die überlieferten Texte über König Matthias immer wieder aktualisiert, aber auch popularisiert. Matthias wurde sowohl als historische Gestalt als auch als ideologisierte Figur aus der Geschichte Ungarns zunehmend „missbraucht“, um die drückenden gesellschaftlichen und politischen Probleme, bzw. die oft opponierende oder den Habsburger Herrschern gegenüber rebellierende Haltung der ungarischen adeligen Schicht mit einem Vorgänger, mit einem als „,national ungarisch“ dargestellten König begründen zu können. Auch das später feststellbare „Versinken“ seiner Figur in das Kulturerbe des Volkes, eine „Folklorisierung“, die Übernahme der Motive in die Texte der Volksliteratur stützen sich hauptsächlich auf diese Elemente der romantisch-nationalen Geschichtsschreibung.

\section{König Matthias in der ungarischen Kulturgeschichte}

Die kulturhistorische Tradition in Ungarn bedient sich hauptsächlich des Vorbildcharakters des Matthias, sowohl für die führenden Schichten als auch für das Volk des Landes. Die Nachwelt erlebt mit Hilfe der Überlieferung einen ,idealen Herrscher“ in der Person von Matthias. Natürlich werden immer wieder aktuelle Schwerpunktverschiebungen bei der Charakterisierung vorgenommen, doch reichlich tauchen feste Tugenden und Wesenszüge des Königs auf, die seine Position, seinen europäischen Rang unterstreichen und somit natürlich das Gewicht Ungarns betonen.

Eines der tatsächlich eminenten Merkmale des Regnums von Matthias bestand in der raschen und erfolgreichen Übernahme, in der Anpflanzung der Ideen des Humanismus und in der Entfaltung der Renaissance in seinem Königreich. In dieser Hinsicht spielte Matthias eine epochenwendende Rolle, er hat tatsächlich das Ende des Mittelalters außerhalb der traditionellen Machtund Kulturzentren des Kontinents eingeläutet. Seine Herrschaft verbindet noch einmal leuchtend grandios in der Kultur und gleichzeitig tragisch in den Konflikten die mittelosteuropäische Region mit den kulturellen und politi-

15 Zitiert von Gömöri 1994, S. 115-6. 
schen Zentren des Kontinents (Italien und Deutschland), bevor die gesamte Umgebung in dem erbarmungslosen Kampf gegen das Osmanische Reich nicht nur unterliegt, sondern ihre Kohärenz und Stärke, ihre raison d'être verliert. Visionen bezüglich der Zukunft, materieller und gesellschaftlicher Fortschritt, Würde des Einzelnen und Kultur der Gemeinschaften leiden von nun an für Jahrhunderte unter dem physischen Überlebenskampf der einzelnen Länder. Zutreffend stellte Dezső Keresztury im Zusammenhang mit der Bedeutung von König Matthias in der Kulturgeschichte das Folgende fest:

An seinem Hofe beginnt die Laufbahn des großen Erzbischofs Johannes Vitéz (1408-1472), der die Grundlagen des Humanismus der königlichen Hofkanzlei legt und der gemeinsam mit dem berühmten Heerführer Johannes Corvinus (1385-1456), dem Vater des Matthias, die erste Phase der Entwicklung bestimmt. Neben dem praktischen, politischen Zwecken dienenden, tatenfrohen Humanismus des Vitéz entfaltet sich die individualistisch-ästhetische Geisteswelt des Poeten, dessen dichterischer Ruhm zuerst die ungarischen Grenzen überschreiten konnte: Janus Pannonius [1434-1472]. In seinen Werken lässt sich die allmähliche Herauslösung der weltlichen, privatmenschlichen und nationalen Inspiration aus den Bindungen des mittelalterlichen christlichen Universalismus am klarsten verfolgen...

Nicht nur das Ausmaß der Corvinischen Renaissance ist also bemerkenswert, sondern auch ihre organische Fülle und ihr verhältnismäßig festes Gefüge.

Mit dem Tode von Königs Matthias verliert sie zwar das einheitliche Kraftzentrum, mit dem allmählichen Zerfall werden aber ihre Ergebnisse [in] immer weiteren Kreisen bekannt. Die nach politischer Machterweiterung strebenden ParteiHumanisten beschleunigen den Prozess der Laizisierung; mit den Jagellonen mehren sich auch immer mehr die Einflüsse der westlichen und nordischen Renaissance. Die aristokratische Elite bröckelt ab und übergibt ihre geistigen Güter der „kleinen Kanzlei“ und dem Mitteladel. Der Humanismus verbreitet sich allmählich als sinkendes Kulturgut (.... ${ }^{16}$

Entsprechend diesen gesellschaftlichen und politischen Veränderungen ist aus dieser humanistischen Tradition, aus der höfischen Kultur und aus dem überlieferten epischen Material bereits ein Jahrhundert später Volksmusik, Volkstanz, Volkskunst geworden und eine ,gesungene Literatur“ entstanden, kompiliert, vorgetragen hauptsächlich von den wandernden „Chronisten“ der Zeit.

Das Ende der Herrschaft von Matthias markiert wichtige, ja weltpolitische Änderungen außerhalb Ungarns - zwei Jahre nach seinem Tod wurde Amerika entdeckt - und auch innerhalb des Landes ist eine neue Phase angebrochen. Matthias hat in der Geschichte, in der Kultur und Kunst in einem seltenen Fokuspunkt gestanden: nahezu alle bedeutenden Figuren der Zeit treffen ihn oder stehen mit ihm in schriftlichem Kontakt, Päpste, der Kaiser, Könige, Kriegshelden, Künstler, Gelehrte, Bücher der Antike, Ideen der ,devotio moderna" und wohl in Folge seiner Abstammung etwas richtungweisend Neues, das einfache Volk. Die vielen Texte, die eine Begegnung von sehr

16 Keresztury 1936, S. 78. 
verschiedenen Vertretern des Volkes mit diesem König beschreiben, eröffnen den Weg seiner Figur in die Reihe der Volkshelden, der Märchenfiguren, der Sagengestalten. Diese mündlich übertragene Epik ist in Bezug auf ihre Menge, Vielfalt und auch in Bezug auf die sie kennzeichnenden epischen Elemente einmalig unter den Herrschern Ungarns:

Es ist ein Fakt, dass auch in der ungarischen Folklore die Figur und das Andenken von König Matthias von der umfangreichsten Tradition in der Volksdichtung, insbesondere von einem Narrativ mit Märchen- und Sagencharakter (die Verbreitung dieser Traditionen im ungarischen Sprachraum kann beinahe als gewöhnlich bezeichnet werden) umwoben wird, und genießt unangezweifelt sowohl die größte Bekanntheit als auch die größte Popularität. ${ }^{17}$ (Übersetzung von T. F.)

In zwei konkreten Fällen hat König Matthias in der ungarischen Kulturgeschichte nachhaltige Spuren hinterlassen, obwohl heute die objektiven Folgen seiner diesbezüglichen Aktivitäten nur in Fragmenten oder überhaupt nicht mehr vorhanden sind. Beide dieser Fälle hängen mit seiner viel gepriesenen Eigenschaft als Gönner und Mäzen der Kultur und der Kunst zusammen. Seine Bibliothek und eine von ihm in Pressburg gegründete Universität sind die glänzendste Beispiele dafür, dass dieser Ruf von ihm berechtigt ist.

Eine einmalig bedeutende Rolle spielt in der ungarischen kulturhistorischen Tradition die in Buda eingerichtete Corvina-Bibliothek von König Matthias als international gewürdigte Hochleistung, als Sinnbild der Kulturauffassung eines Renaissance-Herrschers. Die Bibliothek ist einmalig, was ihre Entstehungsgeschichte, ihren Bestand und was den Inhalt und die Ausstattung der darin aufbewahrten Bücher betrifft.

Die Bibliotheca Corviniana gehört organisch in die Entwicklung der ungarischen Kultur, in die ungarische Buch- und Bibliotheksgeschichte. Eine logische Kette von Ursache und Wirkung führt von dem Vorangegangenen und Gegebenen zu der Bibliotheca Corviniana, die keinesfalls ein Buchmuseum war, sondern eine auf inhaltliche Werte bedachte Bibliothek, entstanden mit dem Ziel, die großen Schöpfungen des menschlichen Geistes zu sammeln, und deren Einfluss auf den mitteleuropäischen Humanismus nicht ausblieb. Der Glanz und Prunk, mit dem die Codices ausgestattet wurden, sollten nur der würdige Rahmen ihres hohen inneren Wertes sein. ${ }^{18}$

Aufgrund unserer Kenntnisse über diese Büchersammlung könnte man zu recht von einem Weltwunder sprechen. Die Bibliotheca Corviniana teilte allerdings das Schicksal der meisten menschlichen Wunder der Kulturgeschichte, sie wurde mit dem Tode von Matthias ihres Schöpfers und Gönners beraubt. Damit begann der Zerfall der von den Zeitgenossen nach der Bibliothek des Vatikans als zweitgrößte bezeichneten Büchersammlung Europas.

17 Magyar 2001, S. 129-30.

18 Csapodi 1982, S. 7. 
...schon zu Wladislaws Zeiten begann die Verschleppung der wertvollsten Codices, und unter Ludwig II. ging es noch ärger zu. Findige Gesandte und ausländische Humanisten verschafften sich lateinische und griechische Codices aus der Bibliothek, und man muss sagen, zum Glück, denn das Verschleppte blieb erhalten. ${ }^{19}$

Über den gesamten Bestand der Bücher in der Bibliothek kann heute nur mit Hilfe von Rekonstruktionen und mit Auswertung des erhaltenen philologischen Materials (Kataloge, Bestellungen, Briefverkehr, etc.) spekuliert werden. 36 Jahre nach dem Tode von Matthias, in Folge der verlorenen Schlacht von Mohács, müssen 1526 der königliche Hof und die Witwe des Königs aus Buda fliehen. 1541 wurde das inzwischen verwahrloste Buda von den Osmanen erobert, und die Bücher der Bibliothek werden in der folgenden Zeit stückweise abhanden kommen. Christliche Soldaten haben erst 1686, nach der Rückeroberung der Stadt, die Räume der einstigen Bibliothek betreten, sie haben aber nur 300 Bände, die weniger wertvollen Reste des Bestandes aus der königlichen Schlosskapelle, vorgefunden. Unter den ungarischen Gelehrten lebte aber in dieser Zeit über 150 Jahre lang eine Legende und die Hoffnung über eine unversehrte Bibliotheca Corviniana weiter.

Heute sind 216 Bücher in den größten und berühmtesten Buchsammlungen der Welt als aus der Bibliotheca Corviniana stammende Exemplare bekannt. Davon werden 53 in Ungarn aufbewahrt, der Rest befindet sich in 49 verschiedenen Bibliotheken in 16 Ländern. Aber die Geschichte der Bibliothek von König Matthias ist noch nicht am Ende, denn es sind noch viele Büchersammlungen der Welt unter dem speziellen Gesichtspunkt der Suche nach Büchern aus dieser legendären Sammlung nicht durchforscht worden, die Ermittlung des gesamten Bestandes geht weiter. Im August 2004 wurden z.B. bei einer französisch-ungarischen Expertentagung weitere drei mittelalterliche Codices in Besançon in dem sogenannten Granvelle-Nachlass ermittelt, von denen angenommen wird, dass sie aus der Bibliothek von König Matthias stammen könnten.

Angesichts der philologisch ermittelten ursprünglichen Größe der Sammlung in der Bibliothek sind aber die oben erwähnten Zahlen der weltweit heute bekannten Exemplare sehr bescheiden, den Berechnungen nach belaufen sie sich lediglich auf etwa ein Zehntel des ursprünglichen Bestandes.

Legt man alle in Betracht zu ziehenden Umstände auf die Waagschale - wie ÄuBerungen der Zeitgenossen, Analogien der italienischen humanistischen Fürstenbibliotheken, die mutmaßliche Größe der Bibliotheksräume in Buda und die Art der Unterbringung der Codices, die wahrscheinliche Anzahl der von den Vorfahren geerbten Bände, das annehmbare Tempo bei den Anschaffungen und $\mathrm{Ab}$ schreiben der Handschriften in den verschiedenen Entwicklungsphasen der Bibliothek, so kommt man mit ziemlicher Sicherheit auf 2000 bis 2500 Bände,

19 Ebd., S. 30. 
Handschriften und gedruckte Bücher zusammengenommen, wobei jedoch die Zahl der gedruckten Bücher verhältnismäßig gering gewesen sein muss. (...)

Als Ergänzung der königlichen Bibliothek können die im selben Schloss verwahrte kleinere, etwa aus 50 bis 100 Bänden bestehende Sammlung der Königin Beatrix und ferner etwa in gleicher Anzahl die prächtigen liturgischen Bücher der königlichen Schlosskapelle angesehen werden; dazu noch die überwiegend theologischen, kirchenrechtlichen, liturgischen Bücher, Predigtsammlungen der Priesterschaft, die der König für die königliche Kapelle bestellt hatte, mit etwa 600 bis 800 Bänden. Alles zusammengenommen darf man also den Bestand der unterschiedlichen Sammlungen auf Schloss Buda auf 3000 Bände schätzen. ${ }^{20}$ (Hervorhebungen von mir T. F.)

Was Wert und Bedeutung dieser Bibliothek betrifft, kann man der ungezügelten Phantasie nur mit den heute vorhandenen Restexemplaren der einst zum Bestand gehörenden Bücher einige Grenzen setzen. Die Verbreitung der humanistischen Ideen, die mittelosteuropäische Renaissance, die regional so bedeutende Bildung an den Universitäten von Wien und Krakau stehen gewiss in engem Zusammenhang mit dem Zerfall der Bibliothek, mit dem Wegtragen des Bücherbestandes aus der Bibliotheca Corviniana. Zahlreiche, später entstandene Übersetzungen vor allem von griechischen Autoren kann man eindeutig auf einst in der Bibliothek von Buda aufbewahrte, überwiegend im Auftrag von König Matthias angefertigte Codices als Quellen zurückführen.

Die Zahl an sich sagt indessen nicht viel aus. Nicht die Zahl der Bände, sondern die Zahl der Werke gibt den Ausschlag. Denn ein und derselbe Codex enthält sehr oft mehrere Werke, nicht selten auch von verschiedenen Autoren. Untersucht man nun den Bestand, indem man die Werke und nicht die Bände zählt, und zieht dabei nicht nur den erhalten gebliebenen Restbestand der Corviniana in Betracht, sondern auch die Angaben, aus denen man von dem Vorhandensein inzwischen verlorener Werke Kenntnis erhält, oder auf solche zumindest schließen kann, hat man erst einen richtigen Begriff von dem Reichtum der Corviniana und davon, wie vielseitig sie war, und ist gar nicht mehr so weit von dem real erscheinenden Vorhaben entfernt, eine vollständige Bibliothek - im humanistischen Sinn - zu sein. Nach unseren bisherigen Forschungsergebnissen kann die Zahl der von der Corviniana erhalten gebliebenen oder sicher nachweisbaren Werke auf 650 geschätzt und rückschließend der Bestand der Königlichen Bibliothek um das Jahr 1490 mit etwa 4000 bis 5000 Werken angenommen werden. (In dieser Zahl ist der theologische Bücherbestand der erwähnten Schlosskapelle nicht erhalten. $)^{21}$

(Hervorhebung von mir, T. F.)

Bereits zu Beginn seiner Herrschaft befand sich Matthias in einem humanistisch geprägten, gebildeten Kreis der höchsten kirchlichen Würdenträger seines Landes. Die bis nach Neapel reichenden Kontakte der Anjou-Könige sind in der Zeit des Königs/Kaisers Sigismund nicht abgeebbt, zahlreiche ungarische

20 Ebd., S. 25-6.

21 Ebd., S. 26. 
Studenten besuchten italienische Universitäten und brachten neue Ideen nach Ungarn mit. ${ }^{22}$

Diese Einflüsse aus Italien haben auch für die Bildung, für den Gedanken einer höheren Einrichtung zur Ausbildung der Würdenträger im Lande selbst immer wieder einen neuen Impuls gegeben. Den ersten Versuch zur Gründung einer Universität hat Ludwig der Große 1367 in Pécs unternommen, auch Sigismund versuchte 1395, eine Universität in Alt-Buda zu etablieren, doch diese Versuche blieben nicht lange am Leben. Der Mentor der HunyadiKinder, der Bischof von Várad, János Vitéz (um 1408-1472), der im Laufe seiner langen, noch unter Sigismund begonnenen diplomatischen und kirchlichen Karriere zahlreiche Kontakte zu führenden Persönlichkeiten (unter anderem mit Aeneas Silvio Piccolomini, dem späteren Papst Pius II.) geknüpft hatte, war von 1465 Erzbischof von Esztergom und der Wegbereiter des nächsten Versuchs zur Gründung einer Universität in Ungarn. Noch in demselben Jahr hat er zusammen mit dem in Ferrara bei Galeotto Marzio und Guarino da Verona ausgebildeten Bischof Janus Pannonius (1343-1472) dem König den Entwurf zur Gründung einer Universität vorgelegt. Die Idee gefiel auch Matthias und die vielen, einst in Italien studierenden, inzwischen in staatlichem und kirchlichem Dienst stehenden Würdenträger des Landes haben mit den Vorbereitungen begonnen.

Janus Pannonius hat noch im Mai desselben Jahres dem frisch gewählten Papst Paul II. das Ersuchen zur Gründung eines nach dem Modell der Universität Bologna mit entsprechenden Rechten ausgestatteten ,studium generale“ vorgelegt. Der Papst stimmte zu (,fiat, ut petitur"), ${ }^{23}$ Vitéz wurde zum Kanzler der ,vollen“, mit vier Fakultäten ausgestatteten Universität, und Matthias bestimmte den Ort Pozsony/Pressburg zum Sitz der Einrichtung, damit wurde die Universitas Istropolitana ${ }^{24}$ gegründet. Nach der Eröffnung am 20. Juni 1467 gehörten zu den ersten Gelehrten der neuen Universität unter anderem Laurentius de Krompach (gest. 1473), der aus Sizilien stammende Dominikaner Giovanni Gatti, der Dekan und Bibliothekar Nicolaus Schricker de Hüttendorf, die Astronomen Johannes Regiomontanus (1436-1476) und Martinus Bylica de Olkus (1433/34-1493/94).

Als der König nach 1468 gegen Böhmen in den Krieg zieht, haben Vitéz und seine Freunde in dieser Wende eine Gefahr für Ungarn gesehen und wollten Matthias absetzen. Doch Matthias entdeckte die Verschwörung, ließ Vitéz einsperren, und mit dem Tod (1472) des Kanzlers verlor die Universität ihren wichtigsten Unterstützer. Sie stellte ihre Tätigkeit schrittweise ein, und Matthias wendete sich in seiner politischen Orientierung zunehmend den österreichischen Ländern zu. Während seiner Wiener Jahre nach 1485 wirkte sein

22 Siehe Tarnóc 1994.

23 Ebd., S. 19.

24 Wesentlich bekannter unter der späteren, seit dem 18. Jahrhundert gebräuchlichen Bezeichnung „Academia Istropolitana“. Siehe dazu Klaniczay 1990. 
dortiger Hof weiter als Magnet auf die Gelehrten aus allen Ländern und sie gründeten nach dem Tode des Königs die aus je einem „contubernium“ in Wien und Buda bestehenden Sodalitas litteraria Danubiana, unter der Leitung von Konrad Celtis (1459-1508). Der Versuch der Gründung einer Universität in Ungarn war wieder einmal durch die Abwendung der Gunst des Gönners gescheitert, doch die Legende einer gelehrten Versammlung um den König lebte in der Tradition weiter. Eine dauerhaft funktionierende Universität entstand erst 1635 auf dem Gebiet des Ungarischen Königreichs.

\section{König Matthias in der ungarischen Literatur}

Das literarisch-episch aufgearbeitete Material in der Überlieferung zur Figur von Matthias ist überwiegend in der zweiten Hälfte seiner Herrschaft und unmittelbar nach dem Tode des Königs entstanden. Die Elemente dieser Tradition basieren auf Chroniken und Berichten, die ein historisches Bild bzw. eine Sammlung von zeitgemäßen Klischees über den großen und gerechten Herrscher festhalten. Die am Hofe des Königs weilenden Künstler und Gelehrten haben Matthias neben einigen persönlichen Merkmalen immer wieder in den typischen Positionen (Feldherr, Diplomat, gebildeter Förderer der Künste, schlagfertiger Debatteur, Ritter, Jäger, etc.) eines Herrschers geschildert. Diese Informationen und die darauf später aufgetragenen ideologischen Inhalte haben vor allem in der Zeit der Romantik der Literatur eine unerschöpfliche Fundgrube an Idealvorstellungen gesichert.

Der berühmte Diplomat und lateinischsprachige Dichter seines Hofes, Janus Pannonius, hat bereits am Anfang der Herrschaft von Matthias für den gegen die Türken kämpfenden Feldherren in seinem nach klassischen Vorbildern gestalteten Gedicht gebeten:

Matthias hebt die Fahne gegen Türken,

Der ganze Himmel stehe ihm nun bei.

Die Keule gib ihm, Herkules, du Mars,

Dein Schwert, Athene, deinen Schlangenschild.

Vulcanus, schmiede einen festen Panzer

Wie für Aeneas einstmals und Achill.

Du, Jupiter, beschütze mit dem Schild

Vor jeder Wunde ihn in Kampf und Streit.

Wenn ihr jedoch in Muße leben wollt,

So sendet von der Burg allein den Vater,

Er wäre seinem Sohn der beste Schutz,

Vom Himmel schleuderte er dann den Blitz. ${ }^{25}$

Matthias, der Kriegsherr ist auch in einem der ungarischen Sprachdenkmäler, in dem als Szabács Viadala (Die Belagerung von Šabac) genannten in die Katego-

25 Hermlin 1970, S. 10. 
rie der historischen Gesänge gehörenden Gedichtsfragment aus dem Jahre 1476 verewigt worden. Die türkischen Verteidiger konnten sich nach der Einnahme der Festung vor den Belagerern entscheiden, wohin sie gehen wollten:

Ki akarna, az válnék császárhoz

Avagy magyari Mátyás királhoz;

Wer wollte, kann zum Kaiser (Sultan)

Oder zum ungarischen König Matthias (ziehen); ${ }^{26} \quad$ (Übersetzung von T. F.)

Die schönliterarische Tradition reicht vom bereits zitierten Matthias-Lied ${ }^{27}$ bis in unsere Tage hin, denn der letzte Roman über den König ist unlängst veröffentlicht worden. ${ }^{28}$ Vor allem das Zeitalter der Romantik hat sich der Figur von Matthias gerne zugewandt, denn diese Phase war gleichzeitig der Höhepunkt der adeligen Ideologie in der ungarischen Geschichte. Das erzählende Gedicht Szép Ilonka (Die schöne Helene) von Mihály Vörösmarty (1800-1855) verwendete ein altes Topos aus der Überlieferung über Matthias. Es verewigte den König als Jäger (von Wild und von Frauenherzen), ein Motiv, das in einer Gruppe von Skulpturen heute auch an der Wand des Gebäudes der SzéchényiNationalbibliothek in Budapest auf dem Gebiet der Burg zu sehen ist.

Im Hymnus, also im nahezu zu derselben Zeit entstandenen Nationallied der Ungarn, das 1823 von Ferenc Kölcsey (1790-1838) geschrieben wurde, werden die wichtigsten Herrscher des Landes erwähnt. Neben den Fürsten aus der Zeit der Landnahme, Bendegúz und Árpád, kommt im Gedicht als Höhepunkt der ruhmreichen ungarischen Geschichte auch König Matthias vor:

Őseinket felhozád

Kárpát szent bércére,

általad nyert szép hazát

Bendegúznak vére

S merre zúgnak habjai

Tiszának, Dunának,

Árpád hős magzatjai

Felvirágozának.

Értünk Kúnság mezein

Ért kalászt lengettél,

Tokaj szőlővesszein

Nektárt csepegtettél.

Zászlónk gyakran plántálád

Vad török sáncára,

S nyögte Mátyás bús hadát

Bécsnek büszke vára.
Führtest es an deiner Hand

Einst auf die Karpaten,

Dass ein schönes Vaterland

Seine Enkel hatten.

Wo der Theis, der Donau Lauf

Wälzet seine Wogen,

Wuchsen Árpáds Söhne auf,

Ward ein Volk erzogen.

Reife Ähren wogten stolz

Auf des Tieflands Feldern,

Nektar, Tropfen reinen Golds

Floss aus Tokajs Keltern.

Ließest unsre Fahne glühn

Auf der Türken Türmen

Und die stolze Burg von Wien

Mátyás' Heer erstürmen. ${ }^{29}$

26 Imre 1958, S. 20.

27 Siehe Fußnote 2.

28 Benedek 2000.

29 Hermlin 1970, S. 48. 
Bis zum 20. Jahrhundert ist es außer Matthias nämlich nur Napoleon gelungen, Wien militärisch einzunehmen. Wien mit seinen 25.000 Einwohnern war zu dieser Zeit neben der symbolischen Bedeutung der Stadt als (ein) Sitz der Habsburger zugleich eine europäische Metropole, nur Köln und Prag waren als Städte zu dieser Zeit größer.

Es ist auffallig, dass während in der ungarischen Literatur Matthias häufig als Held von dichterischen Werken auftaucht, in der modernen belletristischen Tradition Ungarns der König als zentrale Figur eines Romans eine deutlich vernachlässigte Rolle zu spielen scheint. Andere historische Gestalten dagegen, wie Frater Julianus, der Dominikanermönch, die Siebenbürger Fürsten, unter ihnen Gábriel Bethlen und Ferenc Rákóczi II., der Anführer des ungarischen Bauernaufstandes György Dózsa (manche von ihnen sogar mehrmals) haben als zentrale Figuren für die Großepik gedient. Matthias' Größe scheint die Schriftsteller veranlasst zu haben, eher seine Zeit zu schildern und Nebenfiguren aus der Geschichte zu Haupthelden zu wählen, nicht den König selbst. Seine Person scheint auch für die begabtesten Künstler zu erdrückend zu sein. So hat z.B. 1892 Kálmán Mikszáth (1847-1910) einen Kleinroman über den „Kinderkardinal“ Ippolito d'Este veröffentlicht ${ }^{30}$, der später sogar mehrmals ins Deutsche übersetzt wurde. ${ }^{31}$ Lediglich ein ungarischer Schriftsteller, der allerdings in der ungarischen Literaturgeschichte nicht in die Reihe der größten eingestuft wurde, Ferenc Jankovics (1907-1971), hat Matthias und seiner Zeit eine romantisch gestaltete Romantrilogie gewidmet. ${ }^{32}$ Seine Person - wieder als eine Art idealer Herrscher im Hintergrund - spielte darüber hinaus nur in einem weiteren erfolgreichen Jugendroman gegen Ende des 19. Jahrhunderts, als die historisierende Geschichtsbetrachtung in Ungarn in allen Kunstgattungen Hochkonjunktur hatte, eine wichtige Rolle. ${ }^{33}$

In dieser fast als Gleichgültigkeit anmutenden Einstellung dem großen König gegenüber fällt dann desto krasser auf, dass Endre Ady (1877-1919), der wichtigste Dichter der vorigen Jahrhundertwende, sich in einem zweiteiligen Zeitungsartikel 1905 an König Matthias wendet und in dieser programmatisch anmutenden Prosa sich über die Lage in Ungarn, über die Zurückgebliebenheit der Gesellschaft und über die Notwendigkeit von revolutionären Veränderungen äußert. In diesem Text benutzt er zum ersten Mal seine in der ungarischen Kulturgeschichte sehr berühmt gewordene Metapher für Ungarn als „Fährenland" zwischen Ost und West, ein Land, das sich immer jeweils nach dem anderen Ufer sehnt, sich nirgendwo festbindet, sich ununterbrochen auf dem Wege befindet, und doch kommt es nie an einem Ziel an. Auch für Ady stellt König Matthias einen archimedisch-sicheren Punkt in der ungarischen Geschichte dar, als in diesem Land das „Licht“, das Wissen und die Kultur mit

30 Mikszáth 1892.

31 Mikszáth 1905 und 1960.

32 Jankovics 1963, 1965 und 1968.

33 Donászy 1892. 
den europäischen Begriffen inhaltlich noch einig gewesen sind. Seit dem ist Ungarn hoffnungslos zurückgeblieben, und den Preis für diese Rückständigkeit, für den nicht-europäischen Bestand in der ungarischen Gesellschaft bezahlen immer diejenigen mit ihren Leben, die eben für mehr berufen sind und zu mehr fähig wären. Er schrieb:

Fähren-Land, Fähren-Land, Fähren-Land: auch in seinen meistbegabten Träumen hat es sich zwischen zwei Ufern hin- und herbewegt: vom Osten nach Westen, aber am liebsten zurück.

Warum haben sie uns belogen, dass die Fähre - eine Brücke sei - ach Potemkin, du heiliger Mensch mit salbenvollen Händen, du hast nur Zarin Katharina getäuscht.

Idealisten und Verbrecher haben sich zusammengeschlossen, sie haben aus den Luft-Steinen der Falschheit Burgen gebaut, sie haben die Welt voll gejauchzt, dass unter den Karpaten Europa ausgebaut worden sei /.../

Sie haben uns nach vorne getrieben, es war nicht erlaubt nach hinten zu gucken, $\mathrm{zu}$ erblicken, woher wir rasend kommen. $\mathrm{Zu}$ erblicken, dass dieses Land einigen Pharaonen gehört, dass Millionen in dreckiger, tierischer Existenz gehalten werden. Die Pharaonen haben gewollt, dass hier Türme und Pyramiden erbaut werden. Ihr Blut und ihre Nerven sollen manche blinden Verrückten zusammentragen: damit sie mit ihnen prahlen können.

Zehntausend Menschen sind nach vorne geeilt, sie sind in den Nerven, im Blut, in den Gedanken, in der Pein, im Durst zu Europäern geworden. Ein überentwickelter Menschentypus ist hier entstanden, der der ungarischen Gesellschaft mindestens hundert Jahre vorausgeeilt ist.

Diese heiligen Boten haben sich nicht mal im Traum vorstellen können, dass in ihren Versen keine Hunderttausende ihnen folgten /.../

Ungarischer Sonnen-König, Ritter der Renaissance, dein später, armer und durstender Schreiber ritzt einen merkwürdigen Text hierhin. Du sollst ihn deshalb nicht rügen, Majestät Matthias Corvinus, weil er einfältig zu sein scheint, und im Gewand des Meisters Attavante ${ }^{34}$ etwas sieht, das nicht existiert und über etwas schreibt, das nicht existiert. So waren sie schon immer, die Schreiber. Nun, auch ich schreibe auf ein solches Stück deines zu Recht berühmten Corvina-Kodexes meine Buchstaben, der von einem vielleicht niemals zur Welt gekommenen ungarischen Menschen nicht mal geschrieben wurde, den dein sehr vorzüglicher Meister, János Vitéz, zurecht verachtet hat, denn er hat seine Gedichte und fiebrigen Träumereien in der bäuerlichen ungarischen Sprache von sich geschrien. Er schreit sogar auch jetzt, dieser unbekannte Kodex wird seitdem ununterbrochen weiter geschrieben, ob man ihn irgendwann lesen kann? Oder ist das nur ein merkwürdiger, großer geistiger Streit, den nun, mit halber Kühnheit jemand vor das Tribunal schleppt, jemand, der bereits viele Nächte hindurch sich darüber gequält hat, dass gut: es lohnt nicht, in Ordnung: es ist ein Golgatha, aber ob es überhaupt möglich ist? Suchen wir nicht etwa Etwas, das es nicht gibt, und das so

34 Meister Attavante (1452-1517), Miniator aus Florenz, der Hersteller der schönsten Corvina-Bände. 
ist, wie dieser Kodex, dessen Ränder ich mit Buchstaben und Zweifeln volldichte $?^{35}$

(Übersetzung von T. F.)

\section{VII. „Mátyás király“ in der ungarischen Folklore}

Die sehr vielschichtigen und umfangreichen Materialien der volkstümlichen epischen Tradition über König Matthias wurden hauptsächlich im Laufe der letzten zwei Jahrhunderte auch wissenschaftlich erfasst. Den Kern dieses Stoffes bilden Texte, die in kaum vorstellbaren Variationen die historisch überlieferten Nachrichten über Matthias weiterverarbeiten. Neben Legenden, Balladenfragmenten, anekdotenhaften Geschichten gibt es sehr viele Märchen über ihn. Die meisten der so überlieferten Texte zeichnen sich aber auch dadurch aus, das sie im Gegensatz zu vielen Folkloretexten irgendwie listig oder lustig oder mit der Vorahnung eines positiven Ausgangs behaftet sind, die Menschen tragen sie also mit Freude und um Freude zu verursachen vor.

(Mátyás) ...ist der einzige ungarische Herrscher, von dem es auch noch fünfhundert Jahre nach seinem Tod in der mündlichen Überlieferung so viele Anekdoten gibt, dass man damit Bände füllen könnte. Der heldenhafte Türkenbezwinger war ritterlich und galant, ein Freund der Armen und Verehrer schöner Frauen. An seinen Namen knüpft sich eine Vielzahl von Geschichten, deren Motive zum großen Teil aus der europäischen Volksliteratur, aber auch aus örtlichen mündlichen Überlieferungen stammen. Jede Landschaft hat ihr eigenes Mátyás-Bild, das in manchen Zügen von dem der benachbarten Region abweicht; und der ungarische Sagen- und Anekdotenkreis um Mátyás deckt sich wiederum nicht mit dem Mátyás-Bild der Ruthenen, der Slowaken oder Slowenen. /.../ All diese hier mit Sorgfalt bearbeiteten Geschichten haben ihre volkstümlichen Varianten, sind sie doch bereits im 16. Jahrhundert aufgetaucht und seit dem 18. Jahrhundert immer häufiger auch in der ungarischen Literatur zu finden. ${ }^{36}$

Matthias taucht typischerweise in den beliebtesten und meistverbreiteten Geschichten niemals in seinem königlichen Gewand auf. Er kommt immer wieder verkleidet, als Ritter mit heruntergelassenem Visier, als einfacher Bettler oder anderes Mitglied des Volkes in die Geschichte, gleich den orientalischen Legenden um den Kalifen Harun al Raschid, damit er dann, als gerechter Herrscher, die zahlreichen, auch von ihm persönlich erfahrenen oder gar erlittenen Ungerechtigkeiten gegenüber den normalen Untertanen rächen kann. Die Figur des unerwartet, aber meistens in der Notsituation auftauchenden Herrschers, der auch nach seinem Tod im Verborgenen, im Fernen oder an einem geheimen Ort weiterlebt und von dort aus beschützt, verbindet im Falle von Matthias einerseits die ähnlich ausgestalteten religiösen Legenden (z.B.

35 Ady 1905, S. 18.

36 Kovács 1988, (Nachwort zum Band), S. 294-5. 
über Ladislaus den Heiligen) in Ungarn mit dem Kyffhäuser-Motiv in anderen, hauptsächlich nicht ungarischen Legenden.

Er ist aber auch ein beliebter Held zahlreicher anderer Geschichten, wo eigentlich die - von Zeit, Raum und anderen Umständen völlig unabhängige, ewige - menschliche Dummheit im Mittelpunkt der Erzählung steht, wo die Figur von Matthias wahrscheinlich im Laufe der Entwicklung dieser folkloristischen Texte eine Art „Anlass“ geworden ist, um eine von der Person und Figur des Königs völlig unabhängige Geschichte mit der dazu gehörigen Lehre erzählen zu können. Die Gattung solcher Texte, die ziemlich viel Dummheit schildern, ist international gut bekannt, in Deutschland nennt man sie Schildbürgergeschichten. Die ungarische Ortschaft, in der solche Vorkommnisse sich als natürliche ereignen, heißt traditionell Rátót:

\section{König Mátyás und die Rátóter}

Als König Mátyás durch Rátót fuhr, brach plötzlich ein Rad seines Wagens, und er musste seine Reise unterbrechen. Natürlich wusste alsbald die ganze Gemeinde, dass sich der König in ihrem Dorf aufhielt, und der Gemeinderat ging sofort hin zu seinem Empfang und geleitete ihn zu seiner Unterkunft. Dann beschlossen sie, ihm ein Gastgeschenk zu überreichen.

Aber was sollten sie ihm schenken? Sie berieten. Einer schlug vor: „Nüsse.“ Aber: „Nein“, sagte der Schultheiß, „keine Nüsse. In Rátót gedeihen die Pflaumen so ausgezeichnet, schenken wir ihm Pflaumen!“

Während König Mátyás sich ausruhte, füllten die Rátóter ihre Körbe mit Pflaumen. Dann sagte der Schultheiß:

"Ich gehe voran. Und ihr macht alles so, wie ich es euch vormache."

Als sie in des Königs Zimmer traten, um die Pflaumen zu überreichen, stolperte der Schultheiß über die Schwelle, fiel hin, und die Pflaumen kollerten über die Diele. Daraufhin stürzten sich alle Gemeinderäte ebenfalls zu Boden und schütteten ihre Körbe aus. Darüber waren die Gefolgsleute des Königs äußerst erbost, griffen nach den Pflaumen und warfen sie den Männern an die Köpfe. Die sprangen auf, liefen hinaus und sagten:

„Unser Schultheiß ist doch ein kluger Mann, er wusste, dass wir Pflaumen schenken sollten - wie wäre es uns ergangen, wenn wir Nüsse in unsern Körben gehabt hätten?"‘37

In dieser narrativen Kategorie der Überlieferung wurde das bekannteste ständige Epitheton von König Matthias herausgebildet und weitertradiert, er wird als „Matthias, der Gerechte“ bezeichnet. Auch die zum geflügelten Wort gewordene, allgemein verbreitete ungarische Redewendung „König Matthias ist gestorben, die Gerechtigkeit ist hin“" kann auf diese Wurzeln zurückgeführt werden.

37 Kovács 1988, S. 211-12. 


\section{König Matthias in der Kunst und in der Bildung}

König Matthias tritt in der Tradition der bildenden Künste und in der Bildung immer als Verkörperung der bereits früher entstandenen, ideologisch unterschiedlich motivierten Vorstellungen über einen Herrscher bzw. über die Größe der ungarischen Nation hervor. Diese Bereiche haben lediglich die vorhandenen Elemente der Überlieferung aktualisiert und einem Ziel oder dem Auftrag entsprechend benutzt.

Die ungarische Musikgeschichte verfügt z.B. über eine romantische Oper von Ferenc Erkel (1810-1893) über den hingerichteten Bruder von Matthias, über László Hunyadi (mit dem Titel „László Hunyadi“). Diese Oper wurde 1844 uraufgeführt und sie gilt seit der Revolution von 1848 in Ungarn als Nationaloper. Wie in vielen Kunstwerken, wird auch hier der eigentliche Held, das Zentrum der Geschichte, mit seiner Abwesenheit hervorgehoben (Matthias tritt in der Oper nicht auf, aber gerade seine Absenz weist auf seine „Notwendigkeit" in der von der Oper nicht erfassten, folgenden Zeit in der Geschichte Ungarns hin).

In der bildenden Kunst kann man von einer kontinuierlichen Präsenz des Matthias in der Geschichte sprechen. Die - tatsächlichen oder vermuteten zeitgenössischen Schilderungen aus dem 15. Jahrhundert von Matthias in verschiedenen Kunstformen (Miniaturen, Skulpturen, Gemälden, Reliefs, Kacheln, etc.) zeigen meistens bloß den Herrscher mit seinen Attributen, ebenso, wie die Stiche und Drucke der nachfolgenden Zeit, die bereits unter Verwendung von früheren Materialien erstellt worden waren.

Die romantische und historisierende Malerei hat in Ungarn die Figur von Matthias selbstverständlich in unzähligen Variationen der tradierten und oft klischeehaften Posen, Anlässe, Ereignisse seines Lebens dargestellt (z.B. Abb. 6, S. 402).

Aber es gibt kein Bild, das den Anspruch erheben könnte, eine ikonographische Funktion für diesen König bekommen zu haben. Diese Funktion haben eher die im öffentlichen Raum aufgestellten Skulpturen von Matthias übernehmen können (z.B. Abb. 7, S. 403), aber diese Darstellungen gehören damit mehr in die öffentlich-politische Tradition im Lande als in die Geschichte der Kunst.

Parallel zur ideologisch motivierten Umformung und Herauskristallisierung des Königs zum idealen Herrscher aus dem Kreise des ungarischen Adels hat ein für viele Phänomene der Renaissance typischer Prozess, der als „Absinken“ bezeichnet werden kann, stattgefunden. Als Ergebnis dieser meistens vom einfachen Volk in der mündlichen Überlieferung durchgeführten Umwandlung der Person des historischen Herrschers steht vor uns heute König Matthias als Märchenheld. Die so entstandenen Texte sind dann in den letzten zweihundert Jahren ein Teil der Lektüre in der Schulausbildung geworden, sie sind seitdem nicht mehr spontane Erinnerung, sondern eher ein Bestandteil der allgemeinen Bildung geworden, wie das auch die Erzähler offen zugeben: 
Eine der schönsten Geschichten von König Mátyás ist die, wie er in Gömör seinen Edelleuten die Winzerhacken in die Hand gedrückt hat. Wie, Kinder, ihr kennt die Geschichte schon? Nun, wie sollt ihr auch nicht? Sie steht ja in euren Lesebüchern, wie sie auch schon in meinem gestanden hat. Aber wir wollen sie dennoch in die übrigen hübschen Geschichten einreihen, die von diesem König überliefert sind, denn täten wir es nicht, wäre es so, als würde man von einem prächtigen

Dolman einen der Edelsteine abschneiden..."38 (Hervorhebung von mir, T. F.)

Eine so veränderte, populäre Herrscherfigur, die in dieser epischen Tradition eigentlich schon zum Volkshelden umgedichtet wurde, bedeutete sogar für die stark antifeudale sozialistische Ideologie keine unmittelbare Gefahr mehr. So wurde in Ungarn in den 1980er Jahren eine sehr erfolgreiche Zeichentrickfilmserie aus den zahlreichen Volksmärchen hergestellt, die König Matthias, den vom Volk geliebten Herrscher, als Haupthelden darstellen.

\section{König Matthias in der Öffentlichkeit und Politik}

Die Elemente einer politisch motiviert überlieferten Tradition der Figur von König Matthias sind meistens aktualisierte Mischungen aus den unterschiedlichen ihn betreffenden weitertradierten Komponenten. Da nach König Matthias die ungarische Geschichte aus dem Blickwinkel der nationalen Interessen über Jahrhunderte eine sehr schwere und verlustreiche Wendung genommen hat, wurde der letzte große König der vorausgegangenen Zeit, eben die Zeit von Matthias, zum Wunsch, zum Vorbild und zum Maßstab verwandelt. Entsprechend einem weit verbreiteten und oft praktizierten Verhaltensmuster, hat man sich in den häufigen Stunden der Not an „Beschützer“ gewendet, sie herbei geschworen, angebetet oder wenigstens in Erinnerung gerufen. König Matthias ist im Laufe der Zeit zu einem festen Element in den zur Verfügung stehenden Vorbildern für die Ungarn als Gesellschaft geworden.

Diese Vorbildfunktion war in der Zeit, als Ungarn sich zwischen dem Habsburger und dem Osmanischen Reich in einer unterworfenen Lage befand, am aktuellsten in Matthias als Kriegsherr, als Heerführer gefunden worden. So taucht er in den Schriften des führenden Dichters und Heeresführers des 17. Jahrhunderts, bei Miklós Zrínyi (1620-1664) auf. Zrínyi sucht Wege zur Erlangung der nationalen Unabhängigkeit Ungarns und findet dabei König Matthias als Verkörperung des Herrschers der Nation. Im Winter von 1656-57 verfasste Zrínyi seine Meditationen über das Leben des Königs Matthias. Obwohl dieser Text eigentlich in die Kategorie der literarischen Tradition gehören müsste, ist er wesentlich komplexer und folgenreicher in der kulturellen Überlieferung geworden, als das bei ,einfachen“ Kunststücken zu beobachten ist, denn in dieser Schrift

38 Ebd., S. 205. 
befasst sich Zrínyi mit der seit der Schlacht von Mohács und der türkischen Besetzung (1541) so oft erwähnten, fast ins Mythologische erhobenen Gestalt des Matthias, des reichen und unbesiegbaren Königs der ,guten alten Friedenszeiten“. Dieses Matthias-Bild nimmt er nun unter die Lupe und lobt, was in Matthias' Lebenswerk für das 17. Jahrhundert vorbildlich ist. Diese Schrift Zrínyis gilt in mehrerer Hinsicht als der erste ungarische analysierende historische Essay. ${ }^{39}$

In den folgenden Zeiten hat König Matthias sehr oft als eine Art ,zurechtgestutzte Fundgrube“ für allerlei Aktualitäten der jeweiligen Politik gedient. Eine besondere Möglichkeit zum Ausdruck solcher Bestrebungen bieten der öffentliche Raum (Straßen, Plätze, Gebäude) und die Mittel und Stätten des öffentlichen Handelns (Geldscheine, Schulen, Einrichtungen, etc. - z.B. Abb. 8, S. 404) an.

Obwohl einerseits im Laufe der Zeit jede gesellschaftliche Schicht ihr eigenes Matthias-Bild entwickelt hat, kann man andererseits die Entstehung und öffentliche Präsentation eines alle Schichten vereinigenden ,nationalen“ Königs Matthias beobachten. Dieser nationale Retter wurde auch 1940 aus Anlass seines damals allgemein angenommenen 500. Geburtsjahres in einer weltpolitisch äußerst gefährlichen Zeit als historisches Vorbild mit deutlich aktuellen Ansätzen angesprochen:

Seine Gestalt ist nicht nur in seinen Werken, nicht nur in der Geschichte, sondern auch in den Sagen und Liedern der Donauvölker, der Magyaren, der Slowaken, der Rumänen und der Serben, ja auch in der deutschen Kunstliteratur verewigt. Sie gewinnt im Laufe der Jahrhunderte immer mehr an symbolischer Bedeutung, sie wurde zu einer Kraftquelle, in der sich das Magyarentum in den schweren Zeiten der völkischen Schicksalsschläge immer von neuem aufrichtete...

Matthias spannte alle Kräfte seines Landes und seines Volkes an, um die europäische Kultur vor dem Einbruch einer europafremden Macht zu schützen. ...Matthias Corvinus wies seinem Lande und seinem Volke den historisch, geopolitisch und kulturell einzig richtigen Weg, den Weg der innigen Zusammenarbeit mit Deutschland und Italien. ${ }^{40}$

Auch wenn diese Aussage inhaltlich zutreffen mag, kann man den gewaltigen Unterschied zwischen den Idealen der zur Orientierung Ungarns dienenden Ländern Italien und Deutschland in der Zeit von Matthias und den Vorstellungen der selben Länder zur Zeit des fünfhundertsten Geburtsjubiläums von Matthias nicht unbeachtet lassen.

Sowohl in der historischen Überlieferung als auch in den konkreten Darstellungen im Laufe der Geschichte Ungarns ist Matthias ein wandelbares und häufig auch manipuliertes politisches Mittel gewesen. Die Erinnerung an den König in der nicht oder weniger von den jeweiligen Aktualitäten abhängigen allgemeinen Volkstradition ist dagegen meist mit festen und eindeutig positiven Attributen ausgestattet, die im Laufe der Zeit nahezu keine Veränderun-

39 Klaniczay 1977, S. 89.

40 von Farkas 1940, S. 171. 
gen vorzeigen. Die Funktion von König Matthias ist in diesem Kontext auch immer klar definiert, er erfüllt eigentlich göttliche Funktionen, wobei er seine menschlichen Züge nicht verliert: Er sorgt für Gerechtigkeit, er schützt die Schwachen und straft die Ungerechten. Zuletzt wurde die Figur von Matthias in Ungarn in den 1980er Jahren, als die weitere Entwicklung im Lande (und in Europa) noch recht unklar erschien, in Erinnerung gerufen. Als Anspielung auf die aktuellen Verhältnisse, nicht ohne einen etwas bedrohlichen Unterton für die aktuelle politische Führung und als Hoffnungsträger für eine gerechtere Zeit, in der nicht die Fassaden und Vortäuschungen das Verhältnis zwischen dem Volk und seinen Vertretern bestimmen:

Er war ein großer König: er hat das Interesse der Politik und den Schutz der geistigen Werte voneinander getrennt.

Er hat jedoch den gegen ihn Sündigenden nicht verziehen.

Und wenn es nötig war, hat Matthias, der Gerechte, mit List, Fallen, Hinterhalt, mit politischen Praktiken seine Gegner eingekreist und gelähmt.

Man erzählt, er mischte sich in Verkleidung des Öfteren unter das Volk.

Die Menschen erinnerten sich an ihn und haben seinen Namen in ihre Gebete gefasst.

Die ihre konfiszierten Besitztümer, ihre verlorenen, fette Einkünfte sichernden Ämter beweinenden Herren haben den schlauen und hinterlistigen König verflucht! Denn, während sie am mit Fahnen geschmückten, festlich gekleideten Nordtor ihrer Stadt mit Blumenteppich, Fanfarentönen, großem Festessen auf die Ankunft der Herrschers warteten, ist Matthias in Verkleidung als Unbekannter durch das Südtor in die Stadt geschlendert, schaute auf dem Markt herum, hat sich mit den Verkäufern, mit den Schaulustigen unterhalten, ist durch die schmutzigen Gassen getrottet, guckte durch die Fenster der Buden, setzte sich auf dem einen und anderen elenden kleinen Hof, wo seine glücklichen und zufriedenen Untertanen lebten, nieder, befragte eine Kinderschar: ob sie heute bereits etwas gegessen hätten - und wie jemand, der seine Sache erledigt hat, setzte er sich auf sein Pferd und ritt weg.

Der Blumenteppich verwelkte, der Braten ist zu Kohle verbrannt, im schlaffen Wind haben die Fahnen schlechtgelaunt geflattert.

Die Fanfaren sind stumm geblieben: Der königliche Besuch ist ausgefallen.

Doch einige Tage später hat Matthias den Stadtrichter und die übrigen Herren mit einem harten Wort nach Buda befohlen.

Keiner von ihnen ist jemals nach Hause zurückgekehrt.

Wenn das einmal passiert ist, kann es auch ein anderes Mal passieren.

Verkleidet bis zum Zelt des Oberbefehlshabers des Feindes zu schleichen und die geheimen Kriegspläne auszuhorchen, ist eine tollkühne Tat. Matthias hat es getan. Es haben auch andere getan: für einen Beutel Gold meldet sich jemand für alles. Doch Matthias war ein mutiger Herrscher. Denn nicht vermessen, sondern unerschrocken mutig muss jener Herrscher sein, der ohne fürstliche Begleitung, unerwartet, verkleidet, als Unbekannter es wagt, sich mit seinen Untertanen zu treffen, sie kennen zu lernen. Matthias war ein großer König: er fürchtete die Wahrheit nicht. Die Menschen, in deren Phantasie die Legende über König Matthias, den Gerechten geboren wurde, haben ihn niemals Gerechtigkeit erteilen sehen. Sie 
wussten nicht, dass Matthias nicht nur ein starker, sondern auch ein ungestümer Herrscher war. Weise und befangen. Mit einer edlen Seele ausgestattet und einer, der das Trinkgelage mag. Mächtig und despotisch: als Besitzer einer grenzenlosen Macht ein großartiger, jedoch fehlbarer Mensch.

Doch die Legende hat das Wichtigste in der Erinnerung der Jahrhunderte behalten: Es gab mal einen großen ungarischer König, der sich vor der Wahrheit nicht gefürchtet hat. Wenn es einen gab, dann kann es mal wieder einen geben. ${ }^{41}$

(Übersetzung von T. F.)

Auch die heutigen Auseinandersetzungen um Matthias spiegeln diese Beschützerfunktion wieder: sein Denkmal in seiner Geburtsstadt Cluj-KlausenburgKolozsvár ist wegen seines Symbolcharakters bis vor kurzem ständiger Streitund Konfliktpunkt zwischen Ungarn und Rumänen gewesen. Das Denkmal wurde 1902 aufgestellt (Abb. 9, S. 404).

Als 1941 nach dem Wiener Schiedsspruch Nordsiebenbürgen wieder Ungarn zugeteilt wurde, hat das Denkmal zusätzlich zu seiner symbolischen Bedeutung weitere, aktualpolitische Funktionen erhalten (Revision der Friedensverträge) und dadurch ist es zum Objekt ideologischer Kämpfe geworden (Abb. 10, S. 405).

Nach dem zweiten Weltkrieg wurde Klausenburg wieder Rumänien zurückgegeben. Der ideologische Kampf zwischen den ungarischen und rumänischen Vorstellungen und Wertungen über Herkunft, Funktion, Position und Identität von König Matthias hat sich verschärft. Die rumänische Geschichtsschreibung vertrat/vertritt die Ansicht, Matthias sei der Herkunft nach ein Rumäne, der aus Großmachtinteressen gegen sein eigenes Volk (den von dem vordringenden Osmanischen Reich eingesetzten eigentlich Gegen- Fürsten von Moldau) einen Feldzug geführt hätte. Dabei hatte er eine - aus ungarischer Sicht und wohl auch objektiv gesehen - kleinere militärische Niederlage erlitten. Um diese Schlacht ideologisch zu instrumentalisieren, vergleichbar mit der Darstellung der Schlacht auf dem Amselfeld im Falle Serbiens, wurde, um eine ,ideologisch korrekte“ eindeutige Positionierung von Matthias aus dem Blickwinkel der rumänischen Geschichtsbetrachtung ableiten zu können, eine ergänzende Tafel (Abb. 11, S. 405) an die Skulptur mit einem „Urteilsspruch“ von Nicolae Iorga (1871-1940) installiert:

Biruitor în războaie, învins

numai la Baia de propriul

său neam, când incerca să

învingă Moldova nebiruită.

Er hat Siege im Krieg errungen,

lediglich sein eigenes Volk hat ihm

eine Niederlage bei Baia bereitet, als er versuchte

die unbesiegbare Moldau zu bezwingen.

(Übersetzung von T. F.)

41 Szigethy 1983, S. 65. 


\section{Zusammenfassung}

König Matthias hat sich in seinem Nachleben scheinbar in mehrere Figuren gespalten. Er lebt in den literarisch tradierten Texten meist als großer, starker Herrscher eines bedeutenden europäischen Landes. Die historische Überlieferung hebt in diesem Zusammenhang zusätzlich seine Bedeutung als Heerführer, als Kriegsherr hervor. Die kulturell ausgerichtete Erinnerung weist gerne auf Matthias, den kultivierten Menschen, den Unterstützer der Bildung, des Humanismus hin. Die Reste seiner prunkvollen Bauten, die erhaltenen Exemplare seiner berühmten Bibliothek rufen einen beispiellos großzügigen Mäzen in das Gedächtnis. Gleichzeitig existiert in der romantischen Betrachtung ein heldenhafter und wandelbarer Held, der sein Amt als König nur ,nebenbei“ ausübt, denn eigentlich besteht sein Leben eher aus restlosem Wandern, Jagden und anderen Abenteuern im eigenen und im fremden Lande. Ein stärker national ausgerichtetes Bild über Matthias betont sein Wirken als „übernationaler Herrscher" des ungarischen Königreichs. Diplomat, Page, Eroberer, mit dem Hofnarr die Rollen tauschender König, Gönner, uneingeschränkte Herrscher und tausend andere Gesichter des Matthias leben miteinander in einem Tableau.

In einer anderen, volksnahen und in den Texten der Volksliteratur tradierten Erinnerung dominieren andere Charakterzüge des Königs. Hier ist er mehr einer von uns, der mit uns einfachen Menschen das Leben teilt und eigentlich sich erst in diesem Zustand wohl fühlt. Da er aber auch eine hohe Würde hat, muss er immer wieder auch diese wahrnehmen, er muss zurückkehren zu seinem Thron. Diese Doppelseitigkeit seines Wesens ermöglicht es ihm, die beiden Dimensionen mit einander korrektiv zu verbinden: Als König setzt sich Matthias für die Rechte und für Gerechtigkeit gegenüber den Armen ein, als verkleidetes ,zeitweiliges“ Mitglied der Gruppe der Armen sorgt er wiederum dafür, dass im fernen Hof und unter den hochgestellten Aristokraten die Realität des alltäglichen Lebens nicht völlig in Vergessenheit gerät. Er verkörpert den idealen Herrscher, der den Zugang zu den von ihm Beherrschten nicht scheut, ja, sogar sucht. Diese vielen Vorstellungen und Überlieferungen vermitteln eindeutig eine Sehnsucht nach Verhältnissen, die - nicht nur in der Geschichte Ungarns - eine Seltenheit sind. Aber glücklich sind jene Kulturen, jene Menschen, die die Möglichkeit überhaupt haben, in schweren Situationen sich so etwas vorzustellen oder an so etwas erinnern zu können.

\section{Literaturverzeichnis}

Ady, Endre, 1968: „Ismeretlen Korvin-kódex margójára“ [An den Rand eines unbekannten Corvin-Kodex], in: Ady Endre Összes Prózai Müvei [Sämtliche Prosawerke von Endre Ady] VII. Budapest. 
Bak, Janos M., 1973: Königtum und Stände in Ungarn im 14.-16. Jahrhundert. Wiesbaden.

Benedek, Szabolcs, 2000: Mathias Rex. Budapest.

Bonfini, Antonio, 1936-1941: Rerum Ungaricarum Decades I-IV. (Iványi, Bela / Juhász, Ladislaus, Hrsg.). Leipzig, Budapest.

Camerarius, Philip, 1621: The Living Librarie or Meditations and Observations... London.

Csapodi, Csaba / Csapodi-Gárdonyi, Klára, 1982: Bibliotheca Corviniana. Die Bibliothek des Königs Matthias Corvinus von Ungarn. Budapest.

Donászy, Ferenc, 1892: Egy magyar diák Mátyás korában [Ein ungarischer Student in der Zeit von Königs Matthias]. Budapest.

Dümmerth, Dezső, 1985: A két Hunyadi [Die beiden Hunyadis]. Budapest.

Farkas, Julius von, 1940: Matthias Corvinus. Ungarische Jahrbücher XX, 171-2.

Gömöri, George, 1994: „,The Image of János Hunyadi and Matthias Corvinus in 16th-17-th Century England“", in: Klaniczay, Tibor / Jankovics, József (Hrsg.): Matthias Corvinus and the Humanism in Central Europe. Budapest, 109-118.

Happelius, [Everhardus], 1688: Kurzbündige Beschreibung des Königreichs Ungarn. O. o.

Heltai, Gáspár, 1575: Chronica az magyaroknac dolgairól... [Chronik über die Angelegenheiten der Ungarn...]. Colosvar [Klausenburg].

Hermlin, Stephan / Vajda, György Mihály (Hrsg.), 1970: Ungarische Dichtung aus fünf Jahrhunderten. Berlin, Weimar.

Hoensch, Jörg K., 1998: Matthias Corvinus: Diplomat, Feldherr und Mäzen. Graz, Wien, Köln.

Imre, Samu, 1958: A Szabács viadala [Die Belagerung von Šabac]. Budapest.

Jankovics, Ferenc, 1963: A világveró [Der Weltbezwinger] Budapest.

Jankovics, Ferenc, 1965: A budai napkirály [Der Sonnenkönig von Buda] Budapest.

Jankovics, Ferenc, 1968: A fáklya kilobban [Der Fackel erlischt] Budapest.

Kardos, Tibor, 1983: Ki volt Mályás király? [Wer war König Matthias?] Budapest.

Keresztury, Dezső, 1936: Der ungarische Humanismus. Ungarische Jahrbücher XVI, 77-79.

Klaniczay, Tibor (Hrsg.), 1977: Handbuch der ungarischen Literatur. Budapest.

Klaniczay, Tibor (Hrsg.), 1978: Vom Besten der alten ungarischen Literatur. Budapest.

Klaniczay, Tibor, 1990: „Egyetem Magyarországon Mátyás korában“ [Universität in Ungarn in der Zeit von Matthias], in: Irodalomtudományi Közlemények, 5-6(1990), 575-612.

Kovács, Ágnes (Hrsg.), 1988: König Mátyás und die Rátóter. Leipzig, Weimar.

Magyar, Zoltán, 2001: Halhatatlan és visszatérö hösök [Unsterbliche und wiederkehrende Helden]. Budapest.

Marzio, Galeotto, 1485: De egregie, sapienter, iocose dictis ac factis regis Matthiae.

Mikszáth, Kálmán, 1892: A kis primás [Der kleine Kardinal]. Budapest.

Mikszáth, Koloman (Kálmán), 1905: Der kleine Kirchenfürst. Wien, Leipzig.

Mikszáth, Koloman (Kálmán), 1960: Die kleine Eminenz. Budapest.

Ransanus, Petrus, 1490-92: Epithoma rerum Hungararum. Neapel. 
Szigethy, Gábor, 1983: Vorwort zum Kardos, Tibor: Ki volt Mályás király? [Wer war König Matthias?]. Budapest.

Tarnóc, Márton, 1994: Mátyás király és a magyarországi reneszánsz (1450-1541) [König Matthias und die Renaissance in Ungarn (1450-1541)]. Budapest.

Thuróczy, János, 1473, 1488: Chronica Hungarorum. Buda, Augsburg. 
